\title{
The design of axial shaftless pump
}

\author{
Michal Schmirler ${ }^{1, *}$, Hana Netrebska ${ }^{1}$ \\ ${ }^{1}$ CTU in Prague, Faculty of Mechanical Engineering, Department of Fluid Mechanics and Thermodynamics
}

\begin{abstract}
The axial shaftless pump with a rotary casing has been proposed. The pump is unique in its small space requirements and the ability to draw a liquid with a high content of impurities and fibers. Modern motor with an external commutation was used to propel the pump rotor. The pump can be used for both pumping of liquids and marine propulsion.
\end{abstract}

\section{Introduction}

The blade devices belong to the group of hydrodynamic machines and generally can be divided into machines and engines. The group of blade machines includes pumps, fans, blowers and compressors. The group of blade engines includes turbines (water, steam and gas turbines) and marine propulsions - thrusters. All blade machines can be further subdivided according to the direction of the flow of the pumped fluid to radial, axial and diagonal ones. Generally, the axial blade machines are able to operate with lower pressure drop and higher flow rates than centrifugal machines [1]. Therefore, because of this advantage, the axial blade machines are used as pumps for pumping large volume flows, turbines for the processing of high flow rates at low level differences (Kaplan turbine), and as marine engines.

This paper focuses on a structural design of an axial shaftless pump with a rotated casing. This innovative design has the following advantages, compared with conventional shaft machines:

a) Simpler design, reliability

b) Compact design, small size

c) The possibility of pumping liquids with long fibers, cables - resistant to the entanglement of fibers on the shaft

d) Easy modification of the performance parameters.

\section{Design requirements}

The rotor of an axial pump consists of a hub and a small amount of spatially curved runner blades. The blades do not create a closed channels, their profile is analogous to a propeller of the aircraft, or the wing profile. Therefore, they are also called propeller pumps. The arrangement of the conventional axial pump is shown in Fig.1. Usually the hub of the pump has smooth teardrop shape. The blades of the impeller may be a solid part of the hub or tilting by axis perpendicular to the rotation axis of the hub. The tilting can be performed during an operation or at standstill of the machine - sometimes even by installing a set of new blades. The axis of tilting blades may be firmly connected with a mechanism inside the hub, which is mechanically connected to a control device external to the pump. The disadvantages of such solutions are the dimensions and complexity.

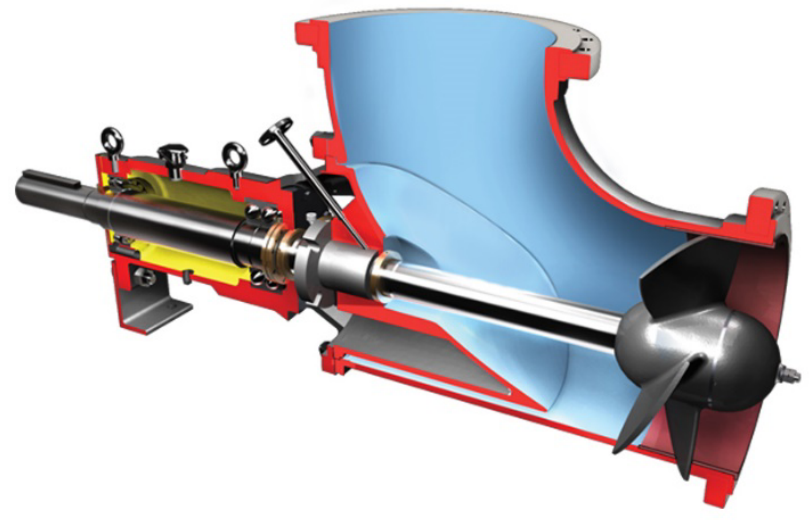

Fig. 1. A conventional configuration of axial pump, here the AFH900 pump (www.flowserve.com)

The requirements for the design proposal of the new pump resulted from the generally known design principles and from the benefits listed above. They are as follows:

a) Simple design - the simplicity of design allows for lower production and service costs. This point was achieved by using mostly cylindrical and round parts, which are based on commercially available blanks and can be produced by conventional machining methods. The need for sealing the output shaft is also eliminated by the use of the shaftless design.

b) Compact design - a very important element in terms of the possible use of the machine. Small dimensions were achieved especially by applying advanced motors with an external electronic commutation.

c) The pumping of liquids with fibers - this requirement is met by using a system with a rotary casing and with the absence of the drive shaft.

\footnotetext{
Corresponding author: michal.schmirler@fss.cvut.cz
} 
d) Modification of the performance parameters the possibility to adjust the parameters according to the customer requirements. The change of performance parameters can be performed simply by replacing the blades of the rotor. One pump casing covers a wide range of operating points.

\section{Design proposal}

So far, this design was used as a marine propulsion and as a propeller of the Micro autonomous underwater vehicles (AUVs). The AUVs need small-scale, powerful and safe propulsion systems especially when they are performing missions in pipes and other confined environments. However, the most conventional propulsion systems do not satisfy all of these three requirements: small, powerful and safe. A micro propulsion systems meeting those requirements are developed based on the RIM propeller concept.

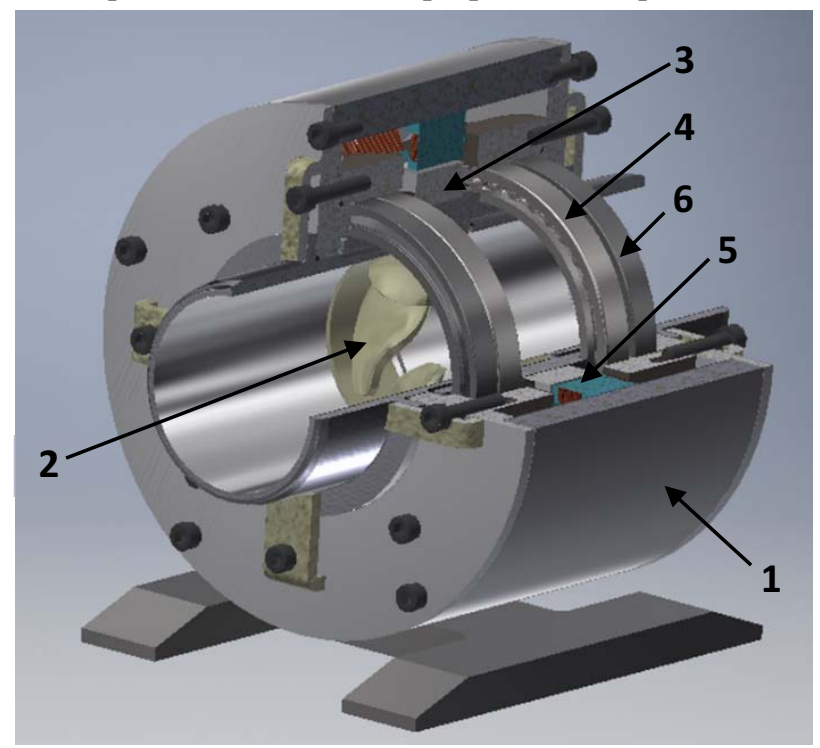

Fig.2. The shaftless pump proposal - schematic view; $1-$ housing, 2 -impeller, 3 - rotor, 4 - bearing, 5 - motor, 6 - rotor seals

The proposed pump (Fig.2.) comes from the same principle as those propellers. The core element of the pump body is the outer shell. In this dimension, it has not been possible to find a suitable tubular duralumin blank, therefore, a thick-walled tube of stainless steel was used. The side flanges are bolted to the shell. For practical reasons, the decision to separate the bearing housings from the bushing flange (lower machining costs) was made. The amount of removed material was also reduced by separating the bearing housings. Both side flanges are identical, made from aluminum rods having an outer diameter of $190 \mathrm{~mm}$. The suction and discharge pipes are inserted outside the flanges. Due to a too small outer diameter of the tubes, it was not possible to mount components screwed directly. The pipes are secured by specially curved washers. The bearing housings are inserted from the inner side of the flanges. They are made of aluminum tubes as well as the flanges. A special edge was used in one of the bearing housing. This edge catches the axial forces in the bearing (Fig.3.). The houses are fitted in the front flange bolts. Half of the screws was chosen longer and extends the curved washers of suction and discharge tubes.

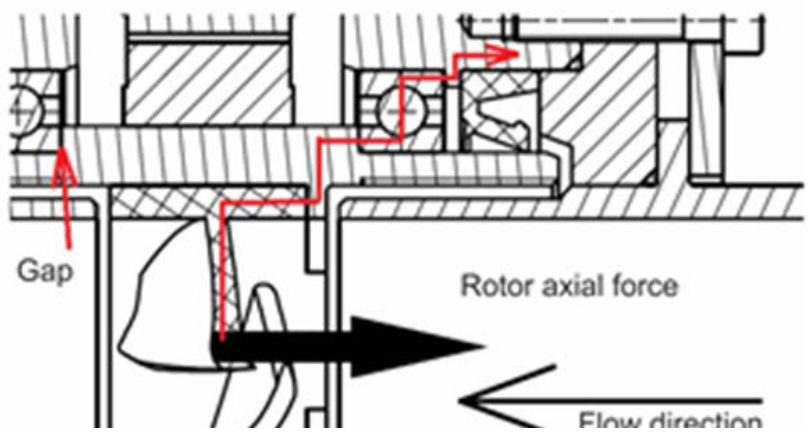

Fig. 3. The axial force reactions in the pump.

Therefore, they can be removed without causing the undesirable release of housings. The sealing of the flange, the suction, the pressure pipe and the bearing housing has been realized by O-rings. The ring with the winding of the electric motor is inserted into the housing and suitably secured, for example, by an adhesive. The wreath with permanent magnets is mounted on the rotor, and again, secured against movement.

The electric motor arranged in a narrow ring will be a part of the machine body. The transmission device and the drive shaft will be omitted. The issue of the pump and a possible utilization of the pump is appropriately described in [2]. This arrangement would reduce the weight and the size of the machine. The ring electric motor, which is a direct part of the machine, is already used in the propulsion water craft. The performance characteristics of this constructed electric motor are fully satisfactory. Relatively to the bigger diameter, a fairly large number of poles is mounted to the circumference of the ring. Therefore, the electric motor is aptly lowspeed and achieves high torque values. The rotor of the electric motor comprises an inner ring, which carries several impeller blades on its inner side. They are oriented perpendicularly to the axis of the rotation. The outer ring (stator) allows the engines to turn along their vertical axis. The turning of the entire drive improves the maneuverability of the vessel. The simplicity of this system has the advantage of a peaceful and quiet operation. It is not necessary to insulate the rotor, only the functional part of the engine has to be hermetically sealed.

\section{Rotor design}

The rotor is composed of a support portion and the impeller. The support portion is mounted in bearings and sealed with shaft seals. Drawing diagram of the entire device is shown in Fig. 4 


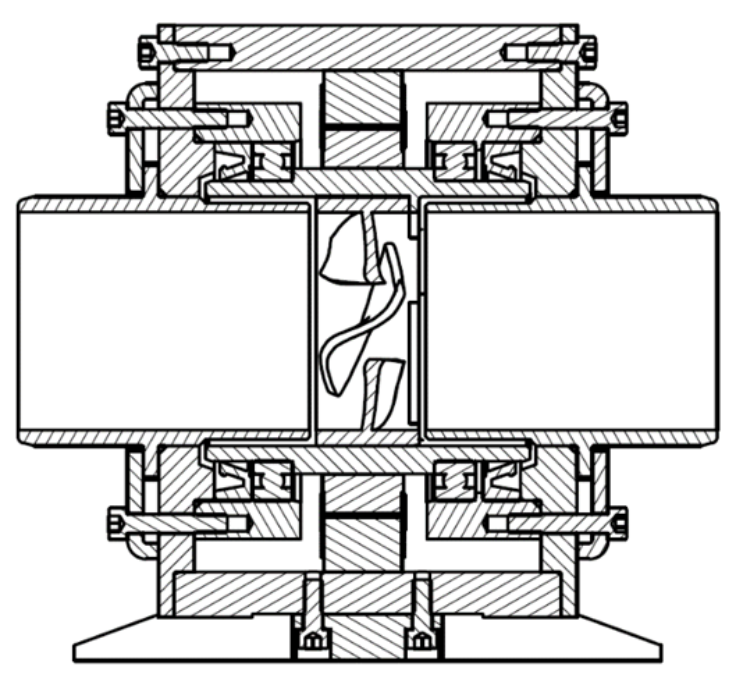

Fig. 4. The drawing of new designed pump with rotated casing.

The pump impeller is designed as a separate part that can be replaced if needed (Fig.5.). The impeller is made by using a $3 \mathrm{D}$ printer.

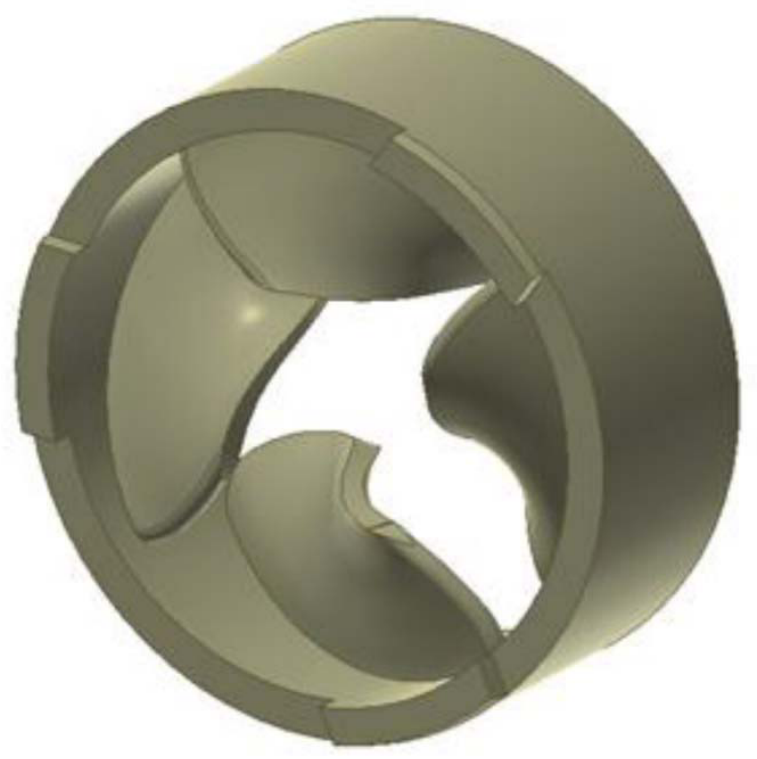

Fig. 5. The model view to the impeller ring.

\subsection{Derivation of the blade geometry}

In this case, the finding of a suitable template to derive the blades from, is not easy. The geometric similarity is not valid, mainly due to the changes in the form (attachment to the outer ring and not to the shaft). In the method described in the preceding paragraph, it is assumed that the experimentally determined parameters of the model (which, in addition, must have a minimal size) are used to convert the parameter to a larger piece, or the entire range of machines. Thus, the conversion may not work in the case of the reduction of the model. The blade thickness is another problem. After the reduction to the desired size, the wall of the blade may be too thin. which could be a complication during manufacturing, in addition to the strength problems that could occur. In the $80 \mathrm{~s}$, an axial pump for suction dredger was developed [3]. The requirement was issued by the Czech Prague shipyard. It was a modification of the pump AA-69-9.9 Sigma Lutin [4], which, at the time, was the top model of the axial pump. Since the medium for a suction pump is a suspension of water with sand and other materials, the main adjustment in the moving blades was their gain to a constant thickness. This changed the blade profile and decreased efficiency, but greatly increased durability. The reinforced profile of the blade is now suitable for a correction to shaftless version and a subsequent reduction. There are a lot of experimental data, including the drawing of the blade [5] for this pump. Original blade geometry is Fig. 6:

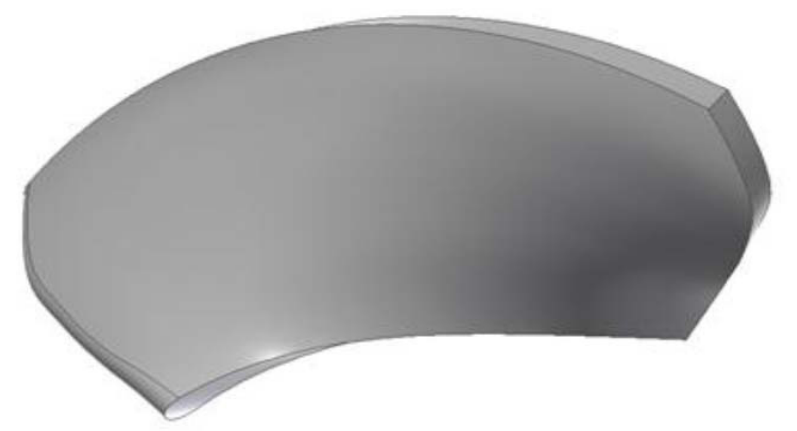

Fig. 6. The original blade from the axial pump AA-69-9.9 Sigma Lutin.

This blade geometry belongs to the wheel with a central shaft. For purposes of the proposed shaftless machine, it was necessary to modify the geometry of the original blade. The new geometry of the blade is shown in Fig. 7.

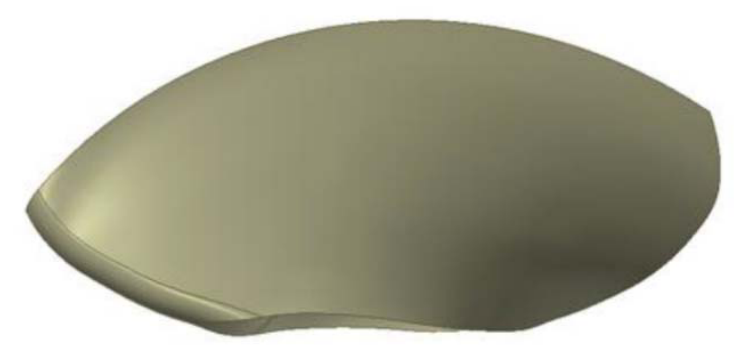

Fig. 7. The modified blade geometry used for new shaftless axial pump.

\subsection{Operating parameters}

The calculation of the pump parameters usually follows the completion of the design of the pump. Those parameters are directly related to the type of used movable blades. The calculation and modeling of a completely new shape of the blades is not appropriate in this case. The solution in the form of geometric similarity of existing blades is far more convenient. Analysis of the problems is described in detail in [6]. The mechanics of material bodies is based on three basic physical quantities. They are length $l$, time $t$ and mass $m$. All the other physical quantities, which are essential 
for hydraulic machinery, are derived from the basic ones. If the original is labeled as a model (M) and the new machine as the real part (D), then the dimensionless basic modules of basic physical quantities can be defined as follows:

$$
\begin{gathered}
\lambda=\frac{l_{D}}{l_{M}}, \\
\tau=\frac{t_{D}}{t_{M}}, \\
\mu=\frac{m_{D}}{m_{M}} .
\end{gathered}
$$

The formulas for recalculation of the model parameters to the real part can be derived using the formulas $(1,2,3)$, if the model parameters are known. For the conversion of specific energy $Y\left(\mathrm{~J} \cdot \mathrm{kg}^{-1}\right)$, flow rate $Q\left(\mathrm{~m}^{3} \cdot \mathrm{s}^{-1}\right)$ and power $P(W)$, the following formulas are deduced:

$$
\begin{gathered}
Q_{D}=\left(\frac{D_{D}}{D_{M}}\right)^{3} \cdot \frac{n_{D}}{n_{M}} \cdot Q_{M} \cdot \frac{\eta_{V D}}{\eta_{V M}}, \\
Y_{D}=\left(\frac{D_{D}}{D_{M}}\right)^{2} \cdot\left(\frac{n_{D}}{n_{M}}\right)^{2} \cdot Y_{M} \cdot \frac{\eta_{h D}}{\eta_{h M}}, \\
P_{D}=\frac{\rho_{D}}{\rho_{M}} \cdot\left(\frac{D_{D}}{D_{M}}\right)^{5} \cdot\left(\frac{n_{D}}{n_{M}}\right)^{3} \cdot P_{M} \cdot \frac{\eta_{h D}}{\eta_{h M}} \cdot \frac{\eta_{V D}}{\eta_{V M}} .
\end{gathered}
$$

The quantities are indicated by indices - $M$ denotes the model and $\mathrm{D}$ denotes the real part. $D$ is the diameter of the impeller, $\rho$ is the liquid density. The revolutions of the machine are labeled $n$. An equally important parameter is the efficiency $\eta$. We distinguish three types of efficiency - volumetric, hydraulic and mechanical. The hydraulic efficiency is experienced primarily at the hydrodynamic machine. Mechanical efficiency is, for simplicity, identical for the model and for the work. According to [7], the volumetric efficiency can also be neglected, because it is not readily determinable and the resultant error is still negligible. Thanks to these simplifying, it is possible to omit the last fraction from

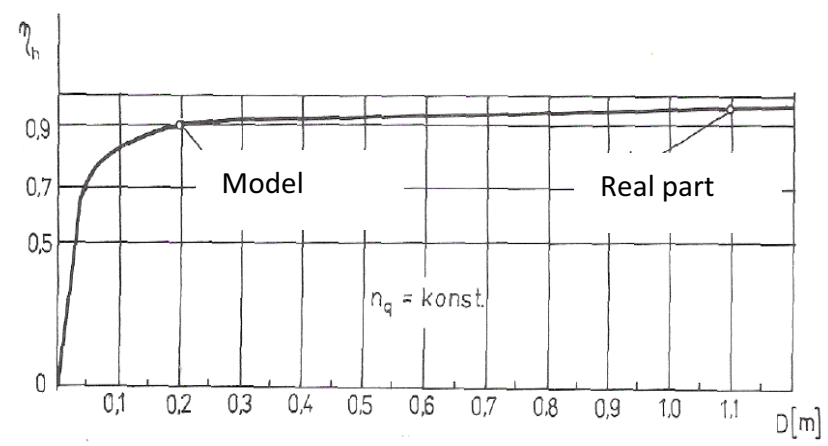

Fig. 8. The dependence of the hydraulic efficiency on the rotor diameter. experimentally) is plotted in Fig. 8. It is recommended to keep the minimum impeller diameter $D_{\text {MIN }}=300 \mathrm{~mm}$, when modeling the test pump [7]. Unfortunately, the new designed impeller has a diameter of only $80 \mathrm{~mm}$. Therefore, the values of the performance parameters obtained by a model similitude were outside the scope. Actual performance values of the new pump will be verified experimentally in the next step of the research.

\section{Conclusions}

A unique shaftless pump with a rotary casing and with an estimated output of $1000 \mathrm{~W}$ has been designed within the project. The main advantages of engineered construction include a small dimensions, simple construction and easy manufacturing. Currently, the documentation is ready and the manufacturing of the pump have started. Upon completion of the production, the performance measurements will be carried out and necessary modifications will be suggested.

\section{Acknowledgement}

This research project has been conducted as part of the industrial research and development project "Advanced Technologies for Production of Heat and Electricity TE01020036" (programme Competence centres), implemented in cooperation between 13 participants and the Czech Technical University in Prague, Faculty of Mechanical Engineering as leading organizational unit, in 2012-2019.

\section{References}

1. J. Blaha, K. Brada, Hydraulické stroje. Praha: SNTL - Nakladatelství technické literatury, 1992. ISBN 80-03-00665-1.

2. P.M. Tuohy, Development of Canned Line-start Rim-driven Electric Machines. Manchester: The University of Manchester, Faculty of Engineering and Physical Sciences, 2011. PhD thesis

3. J. Melichar, Návrh lopatkování a zkoušky axiálního bagrovacího čerpadla. Bratislava: STU, 1999. Strojné inžinierstvo 99 - Conference proceeding. Pp. 313-318. ISBN 80-227-1259-0.

4. J. Spunda, Hydraulický model čerpadla AA-68-9,9. Research report VZ-083/67-Vz: VÚ SIGMA Olomouc, 1968.

5. J. Melichar, Výkonové charakteristiky axiálního modelového čerpadla $\mathrm{s}$ upraveným lopatkováním oběžného kola. Prague: CTU in Prague, 1984. Report České loděnice Praha.

6. J. Blaha, K. Brada, Metoda experimentů a modelování. Prague: CTU in Prague 1995. ISBN 80-01-01236-0. 